\title{
"HAVIA UM SEGREDO QUE SÓ HALIMA SABIA": CONFLUÊNCIAS ENTRE LITERATURA AFRO-BRASILEIRA E MITOLOGIA DOS ORIXÁS
}

\author{
"Havia um segredo que só Halima sabia": confluences between Afro-Brazilian \\ literature and Orixás mythology
}

\author{
Oluwa Seyi Salles Bento*
}

D https://orcid.org/0000-0003-2912-9361

\section{Emerson da Cruz Inácio}

(iD) https://orcid.org/0000-0002-4129-0679

Universidade de São Paulo, Programa de Pós-Graduação em Estudos Comparados de Literaturas de Língua Portuguesa, São Paulo, SP, Brasil. 05508-900 - posdlcv@usp.br

Resumo: Considerando a importância das muitas contribuições do capital cultural africano e afro-brasileiro à nação brasileira, dentre as quais se destacam as religiosas e artísticas, analisaremos a construção de personagens associáveis ao orixá Oxum no conto Fios de ouro, de Conceição Evaristo, parte integrante da obra Histórias de leves enganos e parecenças. Buscamos, neste trabalho, dar ênfase à referência mitológica, a qual não parece ser perdida de vista ao longo do processo de composição do enredo e de subjetivação das personagens na obra evaristiana. Desta forma, nosso propósito é notabilizar a confluência entre produção literária afro-brasileira e o emprego das narrativas e experiências mítico-religiosas e ancestrais africanas e afro-brasileiras, sendo que são parte de um mesmo território epistemológico: a cultura negra no Brasil. Assim, analisaremos a referida obra à luz de trechos dos itàn - textos mitológicos compilados sobre os Orixás -, a fim de identificar possíveis fontes, apontar similaridades e propor caminhos interpretativos.

Palavras-chave: Oxum. Conceição Evaristo. Produção literária afro-brasileira. Textos mitológicos.

Abstract: Considering the importance of the many contributions of African and Afro-Brazilian cultural capital to Brazilian people, among them are the religious and artistic ones, we will analyze the construction of characters associated with the orixá Oxum in the story Fios de ouro, by Conceição Evaristo, integral part of the book Histórias de leves enganos e parecenças. We seek in this this work to emphasize the mythological reference that does not seem to be lost sight of throughout the process of composition of the plot and subjectivation of the characters in the evaristian's work. In this way, our purpose is to highlight the confluence between Afro-

Esta obra está licenciada sob uma Creative Commons - Atribuição 4.0

\footnotetext{
* Até abril de 2020 o artigo circulou com o nome Thaizy Cristhine Salles Bento e que, após mudança de seu nome perante processo judicial, houve essa alteração também nas publicações nas quais é autora.
}

Anu. Lit., Florianópolis, v. 24, n. 1, p. 70-80, 2019. ISSNe 2175-7917 
Brazilian literature and the use of African and Afro-Brazilian mythical-religious and ancestral narratives and experiences, cause they are part of the same epistemological territory: the Black Culture in Brazil. Therefore, we will analyze that previously mentioned story in light of excerpts from itàn - compiled mythological texts about the Orixás -, in order to identify possible sources, point out similarities and propose interpretive paths.

Keywords: Oxum. Conceição Evaristo. Afro-Brazilian literature. Mythological texts.

\section{Introdução}

A literatura afro-brasileira surge quando sujeitos negros brasileiros, conscientes das relações raciais - ou seja, de poder - que sustentam e são indisfarçáveis no Brasil e ao redor do mundo, passam a imprimir, no tempo e na História, suas perspectivas acerca de temas que tocam, das mais variadas formas, a comunidade afro-brasileira (DUARTE, 2011). O racismo, as relações afetivas, a ancestralidade, as marcas relegadas por séculos de servidão imposta são temas recorrentes à literatura afro-brasileira, a qual pode ser considerada privilegiada - e, a cada dia mais o é, na medida que alcança mais leitores e revela mais autores - no processo de dar a conhecer a experiência dos negros no Brasil, e não porque tais temas eram ou são completamente ignorados por escritores e leitores brancos, mas porque os agentes das obras de literatura afro-brasileira deixam como assinatura algo insubstituível, fundamental: a subjetividade negra.

Dentre os temas que povoam as páginas de obras literárias afro-brasileiras, encontra-se a manifestação de religiosidade negra, ou seja, um conjunto de crenças religiosas de ascendência africana, marcadas por experiências sincréticas e ressignificações que são fruto da vivência em solo brasileiro e que resultaram em religiões novas, genuinamente brasileiras, fundadas pela comunidade negra no Brasil e hoje amplamente experienciadas por outros grupos étnicos (SILVA, 2005). O Candomblé, em suas nações de culto, com todo o seu arcabouço míticoreligioso, é um lugar-comum da literatura afro-brasileira na medida que, pela simples referência ao nome de algum Orixá, evoca todo um universo simbólico, de resistência à supressão e à invisibilização e de orgulho pelas raízes negras, tão caro a essa vertente religiosa e que também é uma das mais importantes bandeiras da literatura afro-brasileira, em constante celebração por parte de autores e leitores.

A associação desses dois elementos marcados pela luta por legitimação social e equanimidade de direitos - literatura e religião afro-brasileiras -, realizada por autoras e autores negros, gera um efeito de complementaridade, além de sugerir um contato íntimo e verossímil com a cultura negra. Esse resultado, que pode soar, aparentemente, óbvio, é, na realidade, uma conquista inestimável na medida que garante, em algum nível, que narrativas redutoras ou contraproducentes acerca de sujeitos negros, adeptos ou não às crenças afro-brasileiras, e de sua cultura deixem de ser repetidas e tomadas como sua única imagem possível, pois o olhar e a voz desses, até então, objetos, são os que, agora, percebem e enunciam a si próprios (LEÃO; BENTO; INÁCIO, 2018).

Exemplo desse movimento de tomada do poder enunciativo é a obra de Conceição Evaristo. A escritora mineira, aclamada dentro e fora de sua comunidade, coaduna em sua obra 
o olhar negro, feminino, materno e devoto. Dessa amálgama, assistimos nascer narrativas que, ora criticam, sem perda de efeito estético, a discriminação racial e evidenciam a dura realidade causada pela pobreza, a fome ou o abandono, e ora cedem luz à poesia quase imperceptível do cotidiano de sujeitos - nem sempre de forma explicitada, mas sempre - negros. Na soma, o que parecem ser os aspectos trabalhados por Conceição Evaristo em sua produção literária os quais mais colocam em xeque representações tão naturalizadas e, em mesmo grau, negativizadas dos sujeitos negros na literatura brasileira canônica são a plena possibilidade de serem movidos por sentimentos nobres e a recorrente referência à família e a uma historicidade genealógica que não parte, como regra, da escravização de corpos negros, apesar de não ignorá-la.

Mobilizando justamente esses aspectos, os quais podem ser considerados cardinais na obra de Conceição Evaristo, o conto Fios de Ouro, integrante do conjunto de textos de mesmo gênero intitulado Histórias de leves enganos e parecenças, possui grande semelhança com narrativas mítico-religiosas, especificamente as referentes ao orixá Oxum, bastante conhecidas entre os professantes das crenças afro-brasileiras - nomeadas, no meio religioso, de itàn. Sendo assim, partindo destes pontos que travam diálogo e assumindo que, no grande escopo temático da Cultura afro-brasileira, literatura e religião possuem alguns recursos e fins em comum, intentamos analisar como se dá esse processo de esteticização de Oxum, sem perder de vista os itàn que podem configurar uma fonte de inspiração à memória coletiva e ancestral negra da qual dispõe Conceição Evaristo.

\section{Oxum Halima: uma qualidade possível}

O conto Fios de Ouro é uma narrativa curta, mas muito potente. Esta apresenta um enredo muito pautado pela noção genealógica e pelo poder do feminino, sendo que é justamente o dado de vir ao mundo nessa família específica tendo o gênero feminino que possibilita a experiência extraordinária apresentada no conto. Deste modo, em Fios de ouro, corpos negro-femininos escolhidos pela natureza - a negra mão evaristiana - são assinalados com a potência de modificar a ordem social imposta; os mesmos corpos que, fora da obra, também são assinalados, mas, ao contrário, as ditas marcas compelem à submissão a essa mesma ordem: na obra, os cabelos de ouro possibilitam a liberdade, na sociedade, o fenótipo negroide obriga à escravidão.

O enredo nos apresenta Halima - na verdade, as Halimas: este nome feminino é simbólico no seio desta família negra e sua repetição prediz uma condição em mesmo grau ancestral e mágica. O nome, que possui origem suaíli, significa "suave" (GELEDÉS INSTITUTO DA MULHER NEGRA, 2013) e funciona como um epíteto e como uma herança imaterial, de forma matrilinear e exclusiva às mulheres nascidas com distância cronológica que a narrativa não precisa. Sendo assim, a história de vida da Halima que nasceu antes, em África, é narrada pela Halima que nasceu depois, no Brasil, pentaneta da primeira.

A primeira Halima foi a única sobrevivente de seu clã, ainda criança, à viagem forçada de África para o Brasil. Os ditos "pedaços de relatos" que constroem "uma memória esgarçada" acerca de um conjunto amplo de experiências ao longo da vida desta mulher negra são conservados e passados adiante pela oralidade, uma herança importante e insubstituível frente

Anu. Lit., Florianópolis, v. 24, n. 1, p. 70-80, 2019. ISSNe 2175-7917 
ao mecanismo de aniquilamento físico, epistemológico e historiográfico adotado pelo sistema escravagista. No entanto, sem ignorar aqui a relevância da oralidade, a validade dessa modalidade de transmissão de conhecimento numa sociedade que tanto valoriza a escrita e a oficialidade da História nem sempre é considerada, dado que seu lugar social é adjacente ao das lendas, ou seja, das narrativas que são tidas como puramente ficcionais. No entanto, a história de vida de Halima, nesse sentido, não perde o lastro tradicional da oralidade, mas ganha sua versão sistematizada, escrita, sendo então recontável de diversas formas.

Dentre as experiências de vida de Halima, narradas por sua pentaneta, já na infância podemos identificar correlações com as qualidades, ou seja, arquétipos de Oxum. No Brasil, são conhecidas dezesseis dessas qualidades, as quais possuem histórias, comportamentos, gostos, idades e muitas outras características diversas; elas possuem, no entanto, traços semelhantes importantes, os quais bastam para considerar que todas, apesar das diferenças, sejam apenas manifestações de uma mesma divindade. No geral, os Orixás são interpretados de algumas maneiras diferentes: muitos, como o fotógrafo e enólogo Pierre Fatumbi Verger (2002), afirmam que se tratam de pessoas que de fato passaram, há muito tempo, pela forma humana, mas, graças a suas condutas foram divinizados e hoje são responsáveis pela natureza e pelos seres humanos; outros, como a antropóloga Juana Elbein dos Santos (2012), com uma teoria diferente, defendem que, após a da criação da Terra por Olódùmarè, o Deus Supremo, (NAPOLEÃO, 2011, p. 162) alguns Orixás foram criados; outros, frutos de relações dessas primeiras divindades, nasceram em seguida e lhes foi cedida a posse de forças da natureza e incumbida a proteção à humanidade. Neste artigo, optamos pela segunda hipótese, pois a julgamos mais coerente às próprias narrativas mítico-religiosas, enquanto que a primeira parece sugerir uma influência cristã, como se os Orixás tivessem uma comportamento irreparável a exemplo dos santos católicos ou, pior, como se a cosmogonia destas divindades africanas só fosse possível na medida que tivesse a fé cristã como molde.

Na chegada de Halima em solo brasileiro, nos é apresentado um importante dado cultural de sua comunidade de origem e como este se manifesta em sua aparência: o notável papel do embelezamento dos cabelos. $\mathrm{O}$ uso das tranças - penteados comumente associados à negritude - possui, na obra e na história de tal ornamentação capilar, para além do explícito fim estético, o propósito de indicar a condição econômica, estado civil, faixa etária e outras variáveis sociais. As tranças enraizadas que, durante o período da escravidão, foram utilizadas como mapas de fuga para os quilombos devido a sua possibilidade de formar desenhos, também são conhecidas como tranças nagô, nome de uma das nações do Candomblé e também associado ao povo yorùbá. O termo nagô advém das palavras Ànàgó, que é um subgrupo da etnia yorùbá, de Daomé, o atual Benin (NAPOLEÃO, 2011, p. 46), e Ànàgónu - cujo significado é "pessoa ou povo ànàgó" (SANTOS, 2012, p. 29). À Oxum é atribuída a regência da vaidade e da beleza, além de, segundo um mito que transcrevemos em seguida, ser a criadora da cosmetologia e do cuidado dos cabelos. Em muitos mitos, narra-se Oxum entretida, penteando seus cabelos e admirando sua beleza em seus abèbè - leque espelhado usado por Oxum e Iemanjá - ou nas águas de rios e cachoeiras, seus domínios na natureza. 
Contam que Oxum tinha o cabelo muito comprido. Certa feita, resolveu dá-lo à Iemanjá, em troca de panos de cores muito bonitas. Com o cabelo que ainda lhe restou. Oxum criou lindos penteados, nascendo assim a ciências dos cosméticos e do toucador. (TELLES apud LIMA, 2012, p. 102)

Halima, "com sua vasta cabeleira enfeitada por pequenas conchinhas" (EVARISTO, 2017, p. 49), parece transbordar a beleza de Oxum, pois a descrição da composição de seus cabelos guarda semelhanças com a de mulheres consagradas à deusa afro-brasileira: "trançado com contas e enfeitado com as penas vermelhas do odideré $^{l}$ [...]." (LAKESIN apud LIMA, 2012, p. 60). No entanto, no processo de inferiorização inerente à escravidão, os signos culturais de beleza, os quais denotam humanização, perdem sua demanda social. Sendo assim, a então condição de Halima exige sua marca característica: o corte total dos cabelos. O texto não dá sinais de que a eliminação do cabelo tenha ocorrido por julgarem-no bonito, mas sim pela adaptação à aparência de escravizado e, muito provavelmente, à supressão de símbolos de feminilidade. De acordo com o texto, na passagem "Halima tendo sempre o cabelo cortado, a mando dos que se faziam donos dela e de outros corpos escravizados" (EVARISTO, 2017, p. 50) fica viva a impressão de que as relações de poder encontram reforço e manutenção no processo de, repetidas vezes, cortar os cabelos de Halima até que "esqueceram-se dela, que pouco aguentava trabalhar" (EVARISTO, 2017, p. 50) devido à idade já avançada.

Nos parece impossível não associar a raspagem dos cabelos de Halima com a iniciação de um filho de Orixá no Candomblé. Guardadas suas devidas proporções e afirmando a plena consciência das diferenças nas causas, nos propósitos e nas consequências de cada situação, ambos os processos de corte capilar são bastante simbólicos, posto que dão início a um renascimento: a raspagem ritual sugere um novo nascimento enquanto devoto, sendo que essa noção se espraia por muitos outros aspectos da vida do adepto; a raspagem imposta pela escravidão impõe uma nova vida para o trabalho, de novas obrigações e responsabilidades, novas estratégias de sobrevivência, experiência essa que modifica e dificulta absolutamente tudo na vida do escravizado. Essa comparação parece pertinente porque Oxum é miticamente responsável pela criação da religião e, por extensão, pelo processo de raspagem capilar ritual. Dois belos mitos, os quais transcrevemos abaixo, relatam justamente os momentos em que o corte de cabelo é realizado por Oxum.

\footnotetext{
Um dia, Oxum estava sozinha, muito sozinha... Resolveu então fazer a sua gente. Pegou uma galinha, catulou, raspou e pintou. Colocou na sua cabeça, no seu ori, o oxu. Fez, assim, o povo-de-santo; o primeiro iaô é a galinha d'angola - um bicho que é feito. (VOGEL et al. apud LIMA, 2012, p. 120)

No começo, não havia separação entre o Orum, o Céu dos orixás, e o Aiê, a Terra dos humanos. Homens e divindades iam e vinham, coabitando e dividindo vidas e aventuras. Conta-se que quando o Orum fazia limite com o Aiê, um ser humano tocou o Orum com as mãos sujas. O céu imaculado do Orixá fora conspurcado. O branco imaculado de Obatalá se perdera. Oxalá foi reclamar a Olorum. Olorum, Senhor do Céu, Deus Supremo, irado com a sujeira, o desperdício e a displicência dos mortais,
}

\footnotetext{
1 Odidere é "o nome dado ao, papagaio africano cula cauda possuía penas vermelhas. O mesmo que ikódide." (NAPOLEÃO, 2011, p. 158).
}

Anu. Lit., Florianópolis, v. 24, n. 1, p. 70-80, 2019. ISSNe 2175-7917 
soprou enfurecido seu sopro divino e separou para sempre o Céu da Terra. Assim, o Orum separou-se do mundo dos homens e nenhum homem poderia ir ao Orum e retornar de lá com vida. E os orixás também não poderiam vir à Terra com seus corpos. Agora havia o mundo dos homens e o dos orixás, separados. Isoladas dos humanos habitantes do Aiê, as divindades entristeceram. Os orixás tinham saudade de suas peripécias entre os humanos e andavam tristes e amuados. Foram queixar-se com Olodumare, que acabou consentindo que os orixás pudessem vez por outra retornar à Terra. Para isso, entretanto, teriam que tomar o corpo material de seus devotos. Foi a condição imposta por Olodumare.

Oxum, que antes gostava de vir à Terra brincar com as mulheres, dividindo com elas sua formosura e vaidade, ensinando-lhes feitiços de adorável sedução e irresistível encanto, recebeu de Olorum um novo encargo: preparar os mortais para receberem em seus corpos os orixás. Oxum fez oferendas a Exu para propiciar sua delicada missão .De seu sucesso dependia a alegria dos seus irmãos e amigos orixás. Veio ao Aiê e juntou as mulheres à sua volta, banhou seus corpos com ervas preciosas, cortou seus cabelos, raspou suas cabeça, pintou seus corpos. Pintou suas cabeças com pintinhas brancas, como as penas da galinha-d'angola. Vestiu-as com belíssimos panos e fartos laços, enfeitou-as com jóias e coroas. O ori, a, cabeça, ela adornou ainda com a pena do ecodidé, pluma vermelha, rara e misteriosa do papagaio-da-costa. Nas mãos as fez levar abebés, espadas, cetros e nos pulsos, dúzias de dourados indés. $\mathrm{O}$ colo cobriu com voltas e voltas de coloridas conta se múltiplas fieiras de búzios, cerâmicas e corais. Na cabeça pôs um cone feito de manteiga de ori ,finas ervas e obi mascado, com todo condimento de que gostam os Orixás. Esse oxo atrairia o orixá ao ori da iniciada e o orixá não tinha como se enganar em seu retorno ao Aiê. Finalmente as pequenas esposas estavam feitas, estavam prontas, e estavam odara.As iaôs eram a noivas mais bonitas que a vaidade de Oxum conseguia imaginar. Estavam prontas para os deuses.

Os orixás agora tinham seus cavalos, podiam retornar com segurança ao Aiê, podiam cavalgar o corpo das devotas. Os humanos faziam oferendas aos orixás, convidandoos à Terra, aos corpos das iaôs. Então os orixás vinham e tomavam seus cavalos. E, enquanto os homens tocavam seus tambores, vibrando os batás e agogôs, soando os xequerês e adjás, enquanto os homens cantavam e davam vivas e aplaudiam, convidando todos os humanos iniciados para a roda do xirê, os orixás dançavam e dançavam e dançavam. Os orixás podiam de novo conviver com os mortais. Os orixás estavam felizes. Na roda das feitas, no corpo das iaôs, eles dançavam e dançavam e dançavam. Estava inventado o candomblé. (PRANDI, 2001, p. 526-528)

Antes de chegar à velhice, no entanto, Halima exerceu diversas atividades, dentre elas a condição de mãe-preta, para a qual, afirma a narrativa, fora "eleita". Esta posição, que nada tinha de privilegiada no contexto da escravatura, era cruel e responsável pelo desgaste dos poucos laços familiares que a escravidão não suplantara por completo. Mulheres negras, depois de gestarem e darem a luz à sua prole, eram obrigadas a cuidar e aleitar os filhos de seus algozes (SILVA, 2017). Criavam, sem dúvida, uma relação complexa com essas crianças, pois ao mesmo tempo que desenvolviam algum afeto pelos herdeiros da casa-grande - o que não raro era recíproco - também sentiam falta da sua família e tinham raiva pela distância forçada. No entanto, seja ama de leite, seja mãe biológica, em ambas as situações a veia da maternidade é perceptível em Halima, o que nos possibilita lançar mão de mais uma hipótese comparativa entre a personagem e o orixá Oxum. Na mitologia, Oxum é, via de regra, associada à maternidade: é responsável pela fertilidade, pela menstruação, pela gravidez, pelo líquido amniótico e pelas crianças pequenas, independentemente do orixá a quem pertençam. Além disso, a relação entre Oxum e as crianças é bastante positiva, havendo mitos, inclusive, em que o orixá também vive a fase infantil da vida. 
Orumilá, orixá da sabedoria e da adivinhação, foi o primeiro esposo de Oxum. (...)Infelizmente, Oxum não ficou grávida durante o casamento. De acordo com as tradições africanas, tal fato é uma desgraça, pois filhos são a prioridade de todo casal. Já aflita com a situação, ela resolveu dar a seu marido o direito de ter filhos e, relutantemente, deixou Orumilá.

Nove meses depois, Oxum conheceu seu segundo esposo: Xangô Aieledjê. Os dois descobriram instantaneamente que suas personalidades se completavam, e foram muito felizes como marido e mulher. Entretanto, sua adoração um pelo outro não remediou a incapacidade de Oxum em conceber filhos de seu novo marido. Muito desapontados, eles realizaram vários rituais, sem conseguir nenhum proveito. Mas Oxum não desistiu. Ela conversou com Xangô e ambos concordaram que ela deveria voltar para o seu primeiro marido, o adivinho Orumilá, pedindo que ele consultasse Ifá para apurar o que estava acontecendo.

Quando Oxum chegou à casa de Orumilá, ele ficou feliz em vê-La e foi imediatamente consultar Ifá. Orumilá assegurou a Oxum que esta história de não ter filhos iria logo terminar. Sua solução estava no palácio de Orum, o mundo espiritual: era para lá que Oxum deveria viajar a fim de buscar sua cura. Sua esterilidade se transformaria em fertilidade, e Olodumare, deus supremo, abriria as portas para as crianças virem ao mundo. O adivinho aconselhou Oxum a reunir os itens que haviam saído no jogo, para que se oferecesse um sacrifício especial em sua intenção. Assim foi feito.

Quando se deu por conta, Oxum estava no Orum escutando a voz de Olodumare, que perguntou a ela qual a razão de estar ali. Oxum ficou atônita, e Olodumare pediu que se acalmasse. Depois de oferecer a Oxum um lugar para se sentar, Ele começou a contar histórias de seres que vinham ao Orum para fazer pedidos semelhantes, lembrando que as crianças do Orun fugiam deles sem razão aparente.

Então Olodumare abriu a porta de onde as crianças estavam. Era a visão mais linda que se poderia ter. Oxum olhou maravilhada para uma multidão de meninos e meninas, que corriam para cima e para baixo, em grande algazarra. Quando as crianças viram Oxum, correram em sua direção. Ela então ofereceu-lhes doces, e assim mais e mais crianças aglomeravam-se ao seu redor. Todos foram seguindo Oxum, que se encaminhava para a divisa entre o céu e a terra. Porém, logo que chegaram a este ponto, as crianças pararam abruptamente. Oxum deu às crianças as últimas gostosuras do pote no topo de sua cabeça e voltou para o mundo material.

$\mathrm{Na}$ sua chegada, entretanto, Oxum notou que as crianças não a haviam acompanhado e começou a chorar. Ela se debulhou em lágrimas e contou a Orumilá o que acontecera.

Orumilá aconselhou Oxum a não mais chorar, dando-lhe parabéns. Ele lhe contou que ela estava grávida e deveria parir logo. Não foi de outro modo. Quando Oxum ficou grávida de três meses, outras mulheres estéreis também engravidaram. E, quando a gravidez atingiu o nono mês, nada podia segurar os recém-nascidos que vinham ao mundo. Oxum usou ainda seus segredos para baixar a febre de seus filhos. Orumilá recomendou que as mulheres fizessem oferendas em favor de suas crianças e também de Oxum para demonstrar sua gratidão.

Toda vez que estas oferendas são entregues, deve-se entoar uma cantiga cujo significado é: "Saudações à Grande Mãe; aquela que usa jóias de bronze para acalmar a criança”.

Oxum passou a ser venerada na terra iorubá. Ela curou a febre de todas as crianças, que não tiveram nenhuma dificuldade desde então. Foi assim que Oxum ganhou o título de Irunmalé Olomowewê, divindade protetora das crianças. (LAKESIN apud LIMA, 2012, p. 104-108)

Até o nome de Halima, cujo significado deixa-se transparecer em sua personalidade, remete à Oxum e uma de suas funções: o orixá responsável pela maternidade e pelo sucesso da gestação não pode indispor-se ou nutrir sentimentos negativos por ninguém, nem mesmo por seus inimigos, a ponto de puni-los através da infertilidade (SANTOS apud LIMA, 2012, p. 31). Halima, a narradora, nos relata que "Halima, a suave, apesar de tantas dores acumuladas, desde 
criança nos porões dos tumbeiros, mais se suavizou" (EVARISTO, 2017, p. 50), dado que pode sugerir cansaço, mas também sabedoria.

Quando os algozes de Halima simplesmente deixam de se importar com ela, algo mágico se lhe ocorre: da noite para o dia, todos os cabelos que foram cortados ressurgiram, como se nunca tivessem sido amputados. Transcrevemos abaixo o trecho do conto em que tal situação é narrada.

Um dia Halima acordou e viu seus cabelos surgirem imensos, tão imensos que ela pisava sobre eles. Foi como se todos os fios perdidos (cortados à força) ao longo da vida de Halima, procurassem a dona deles, a cabeça à qual eles pertenciam e viessem novamente para o lugar original, o lugar de nascença. (EVARISTO, 2017, p. 50)

De fato, o comprimento dos cabelos de Halima tem alguma relação com as narrativas mítico-religiosas atribuídas a Oxum, porém, o que acontece em seguida aos cabelos da personagem são um brinde a este artigo que se pretende, no mínimo, coerente. Os cabelos de Halima, depois de sete dias de seu ressurgimento, começaram a apresentar uma mudança de coloração: repentinamente tornaram-se cor de ouro. No entanto, a cabeleira que despertou a curiosidade em todos da cidade, era muito mais que mera cor de ouro: era ouro de verdade. Halima, no entanto, estava ciente de tudo.

Havia um segredo que só Halima sabia. Seus cabelos não pareciam ser de ouro, eram de ouro. Ainda pequena, antes do embarque, seu destino havia sido vaticinado. De tempos em tempos, um pessoa do clã de Halima nascia com cabelos de ouro, que só apareciam depois de longo tempo de maturação da pessoa, quando o tempo começasse a lhe oferecer a dádiva do sábio envelhecimento. Por isso, ela não se desesperava toda vez que os agressores lhe cortavam os cabelos. O ouro nasceria um dia, no tempo exato, mo corpo amadurecido dela. (EVARISTO, 2017, p. 51)

Não causaria espanto caso a narradora do conto nos revelasse que o clã de Halima, em África, é, na verdade, a cidade que existe ao redor do rio Òsun (NAPOLEÃO, 2011, p. 177), na Nigéria, onde se cultua, há séculos, este orixá, tamanha a relação entre a personagem e a divindade. Dentre os domínios de Oxum, encontra-se o ouro. As cores rituais do orixá, suas jóias, os fios de conta que seus filhos carregam no pescoço, seus paramentos: a maioria daquilo que diz-se pertencer a Oxum tem a cor do ouro ou é confeccionado a partir dele.

Halima, consciente do valor de seus cabelos, usou-os para comprar cartas de alforria para si e para muitos outros escravizados que conhecia. Depois, levou todos consigo e construiu, perto de uma nascente cujo simbólico nome era Rio do Ouro, seu novo lar, a Fazenda Ouro dos Pretos, a qual tornou-se uma das mais produtivas do estado e sustentou por muito tempo a descendência de Halima, inclusive sua pentaneta, que herdara seu nome e seus cabelos de ouro: herdou, portanto, a marca de Oxum.

\section{Conclusão}

Conceição Evaristo, em sua produção literária, parece evocar uma memória ancestral e

Anu. Lit., Florianópolis, v. 24, n. 1, p. 70-80, 2019. ISSNe 2175-7917 
compartilhada do povo afro-brasileiro, obtendo, então, como resultado narrativas que amalgamam o maravilhoso, quase impensável, e o mais simples nas coisas. Esse trabalho é valioso na medida que se encaixa numa lacuna dolorosa para muitos membros da comunidade negra: a impossibilidade de recontar sua história genealógica. Nossa história enquanto povo sequestrado é propositadamente pouco conhecida, pouco cognoscível, no geral. A (re)construção de mitos de criação, de chegada, de significado para a vida nos fornece a base mínima para compreender o presente e encarar o devir.

As narrativas mítico-religiosas são, sem sombra de dúvida, o conjunto de mitos fundacionais da comunidade negra. Ainda que para muitos estas tenham perdido o aspecto verossímil ou até mesmo não conste da lista de crenças possíveis, há que, no mínimo, buscar compreender seu valor simbólico, e não ignorar seu aspecto cultural, quando o religioso já se perdeu.

As religiões afro-brasileiras, sob a forma de mitologia dos Orixás, a qual não é menos literatura, apesar de possuir prolegômenos diferentes de outros gênero narrativos - como o princípio de autoria coletiva ou desconhecida, um tom muitas vezes explicativo e uma linguagem simples -, está, junto com a literatura afro-brasileiras, sob domínio da Cultura negra. As relações que, por vezes, não parecem tão nítidas, saltam aos olhos em narrativas como esta de autoria de Conceição Evaristo. A mera possibilidade de encontrar em um ou outro personagem traços de mitos afro-brasileiros, que se fixam em nossa memória coletiva, já soa como um avanço concreto da propagação tanto da literatura quanto das religiões afrobrasileiras. A intencionalidade em representar Oxum é de improvável aquilatação sem a prévia explanação da autora, o que provavelmente apequenaria o efeito estético da coexistência. Ao cabo de alguma reflexão, talvez descubramos que se trata de uma história de leve engano ou parecença.

\section{Referências}

DUARTE, Eduardo de Assis. Por um conceito de literatura afro-brasileira. In: FONSECA, M. N. S. Literatura e afrodescendência no Brasil: antologia crítica. v. 4. Belo Horizonte: UFMG, 2011. Disponível em: http://www.letras.ufmg.br/literafro/arquivos/artigos/teoricosconceituais/Artigoeduardo2conceitodeliteratura.pdf. Acesso em: 20/02/2019.

ELBEIN DOS SANTOS, Juana. Os Nàgô e a morte: Pàde, Àsèsè e o culto Égun na Bahia. Trad. Universidade Federal da Bahia. 14. ed. Petrópolis: Vozes, 2012.

EVARISTO, Conceição. Fios de Ouro. In: EVARISTO, Conceição. Histórias de leves enganos e parecenças. 3. ed. rev. Rio de Janeiro: Malê, 2017, p. 49-51.

GELEDÉS INSTITUTO DA MULHER NEGRA (São Paulo). Significados dos Nomes Próprios Africanos. 2013. Disponível em: https://www.geledes.org.br/significados-dos-nomesproprios-africanos/. Acesso em: 20/02/2019.

LEÃO, Janete F.; BENTO, Thaizy C. S.; INÁCIO, Emerson C. A Representação das mulheres de òrìsà - análise da estereotipia feminina na narrativa de Jorge Amado e Conceição Evaristo. 
Guavira Letras, Três Lagoas, MS, n. 26, p. 92-102, jan./abr. 2018. Disponível em http://websensors.net.br/seer/index.php/guavira/article/view/604/478. Acesso em: 21/02/2019.

LIMA, Luís Felipe de. Oxum: a mãe da água doce. Rio de Janeiro: Pallas, 2012. (Orixás, 6).

NAPOLEÃO, Eduardo. Vocabulário yorùbá: para entender a linguagem dos orixás. Rio de Janeiro: Pallas, 2011.

PRANDI, Reginaldo. Mitologia dos Orixás. São Paulo: Companhia das Letras, 2001.

SILVA, Fabiana C. Maternidade Negra: a representação literária como disrupção do nacionalismo. In: Maternidade Negra em Um Defeito de Cor: história, corpo e nacionalismo como questões literárias. São Paulo, 2017. 209f. Tese de Doutorado (Teoria Literária e Literatura Comparada) - Faculdade de Filosofia, Letras e Ciências Humanas, Universidade de São Paulo. Disponível em: http://www.teses.usp.br/teses/disponiveis/8/8151/tde-28032018104918/pt-br.php. Acesso em: 21/02/2019.

SILVA, Vagner Gonçalves da. Candomblé e Umbanda: caminhos da devoção brasileira. São Paulo: Selo Negro, 2005.

VERGER, Pierre Fatumbi. Orixás: deuses iorubás na África e no Novo Mundo. 6. ed. Trad. Maria Aparecida da Nóbrega. Salvador: Corrupio, 2002.

Oluwa Seyi Salles Bento (oluwaseyi@usp.br) é graduada em Letras - Português pela Faculdade de Filosofia, Letras e Ciências Humanas da Universidade de São Paulo (FFLCH USP) e mestranda em Estudos Comparados de Literaturas de Língua Portuguesa do Departamento de Letras Clássicas e Vernáculas da Faculdade de Filosofia, Letras e Ciências Humanas da Universidade de São Paulo (DLCV - FFLCH - USP).

Emerson da Cruz Inácio (einacio@usp.br) é Professor Associado da Área de Estudos Comparados de Literaturas de Língua Portuguesa do Departamento de Letras Clássicas e Vernáculas da Faculdade de Filosofia, Letras e Ciências Humanas da Universidade de São Paulo (DLCV - FFLCH - USP). Doutor em Letras vernáculas pela Universidade Federal do Rio de Janeiro (UFRJ) e Livre-docente em Crítica Cultural pela Faculdade de Filosofia, Letras e Ciências Humanas da Universidade de São Paulo (FFLCH - USP).

\section{NOTAS DE AUTORIA}

\section{Como citar esse artigo de acordo com as normas da revista}

SALLES BENTO, Oluwa Seyi; INÁCIO, Emerson da Cruz. "Havia um segredo que só Halima sabia": confluências entre literatura afro-brasileira e mitologia dos Orixás. Anuário de Literatura, Florianópolis, v. 24, n. 1, p. 70-80, 2019.

\section{Contribuição de autoria}

Oluwa Seyi Salles Bento: Concepção, coleta de dados e análise de dados, elaboração do manuscrito, redação, discussão de resultados.

Emerson da Cruz Inácio: Discussão de resultados e revisão bibliográfica.

\section{Financiamento}

O presente trabalho foi realizado com apoio da Coordenação de Aperfeiçoamento de Pessoal de Nível Superior - Brasil (CAPES) - Código de Financiamento 001. 
Consentimento de uso de imagem

Não se aplica.

Aprovação de comitê de ética em pesquisa

Não se aplica.

Licença de uso

Este artigo está licenciado sob a Licença Creative Commons CC-BY. Com essa licença você pode compartilhar, adaptar, criar para qualquer fim, desde que atribua a autoria da obra.

\section{Histórico}

Recebido em: 31/03/2019

Aprovado em: 15/07/2019

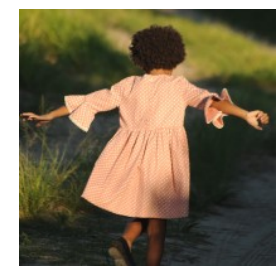

